\title{
Using Technology to Retain Baby Boomers in the Workforce
}

\author{
David Salb \\ ${ }^{1}$ Department of Mathematics and Computer Science, Kingsborough Community College, Brooklyn, NY \\ Correspondence: David Salb, Department of Mathematics and Computer Science, Kingsborough Community \\ College, 2001 Oriental Boulevard, Brooklyn, NY 11235. Tel: 1-718-368-5925, email: dsalb@kingsborough.edu
}

Received: May 21, 2015

doi:10.5539/cis.v8n3p180
Accepted: June 12, 2015

Online Published: July 27, 2015

URL: http://dx.doi.org/10.5539/cis.v8n3p180

\begin{abstract}
Many Baby Boomers (born between 1946 and 1964) are reaching retirement age at the rate of 8000 a day (AARP 2014). Yet, they still have a desire to remain in the workforce and remain active in their professional environment. Over the years they have developed the strong skills and expertise that industry needs. However, some of these cohorts have several age-related limitations that may be of concern to employers. This paper examines some of the technology solutions available to permit this group to remain productive and active in the workforce.
\end{abstract}

Keywords: baby boomers, assistive technology, accessibility aids, disabilities

\section{Introduction}

It is estimated that the workforce of employees aged 55 and over (Boomers) will reach 23 million by 2016 (AARP 2014) and be as high as 33 million by 2025 (Toossi, 2006). This cadre of workers is still in demand since lower fertility and birth rates of Generation X'ers, Generation Y'ers and Millennials have not filled the demand for skilled workers. Baby boomers are filling this gap (Czaja \& Moen, 2004; Ford \& Orel, 2005). Jobs requiring high cognitive skills and solid interpersonal capabilities increased about 35\% between 1971 and 2006 (Johnson, et al 2011). Many jobs requiring skills gleaned from post-secondary education are expected to grow faster than an average of $10.8 \%$ in the next decade (US BLS, 2012). Thus, the demand for the existing set of skilled and educated baby boomer workers will be sustained for quite a while.

Despite this statistically obvious need for the skills of older employees, age related discrimination is believed to be widespread. To protect employees against discrimination federal laws and regulations have been passed and periodically amended.

The Age Discrimination in Employment Act (ADEA, 1975) protects workers over 40 from being fired or being refused employment solely based on their age. This act was passed since employers, at times, discriminate in hiring and retaining older workers in favor of younger ones.

Congress also passed the Americans with Disabilities Act which protects the rights of an individual who can "with 'reasonable accommodations' perform the essential functions of the employment position that such individual holds or desires." (ADA, 1990). What this means is that employers are obligated to provide the means that allow individuals to be employed (or to continue to be employed) in job functions for which they are capable. Although the employer has some discretion in defining what skills are essential to perform the job, what is considered "reasonable accommodations", and what would exempt the employer if providing these assistances would cause "undue hardship", the law is clear in how these terms are defined and to what extent the employer may deny support to the disabled employee.

Section 508 of the Rehabilitation Act (29 U.S.C. 794d), as amended by the Workforce Investment Act of 1998 (WIA, 1998), requires all federal agencies (and the postal service) that when maintenance, use, procurement or development of information technology is done, individuals with disabilities should have similar use and access of such technologies in a comparable way to those without disabilities.

Section 255 of the Communications Act requires manufacturers of telecommunication systems and service providers to develop products that would also accommodate individuals with disabilities. These rules cover all hardware, software components associated with the telephone and telecommunication systems that would be found in a home or office. 
From the employee perspective, there is a desire on the part of baby boomers to stay in the work force for professional, economic and social reasons. (O’Hara-Deveraux , et al., 2001; Gist et al., 1999). Boomers typically enjoy a respected place in the workforce, have established friendships and social interactions focused on their work environment, and often find fulfillment in their work. Older workers often view work in terms of its meaning. They look to serve as mentors and guides for the next generation (Calo et al., 2007). They often also need the income since some Boomers do not have sufficient funds for retirement either because they failed to plan properly or because they lost significant amount of retirement funds due to the stock market and housing bust of 2008 (Journal Property Management, 2012).

Some employers are reluctant to retain older employees because of the high wages they command and the higher cost of health care insurance. Some managers are of the opinion that Boomers are not current on required technology skills and the expense to train them in new technologies is expensive. Other concerns include: a reluctance to adopt connectivity to social media, the perception of lower quality work and being less productive and less mobile since- they are strongly rooted in their communities and less likely to move to other locations more desirable to the company (Kanfer et al., 2004).

Despite these concerns, older workers bring to their companies an expertise not often found in younger and middle aged people. These skills include allowance for compromise, higher order reasoning, viewing a problem from a number of perspectives and recognizing the limits of knowledge (Grossmann et al., 2010). However, employers do face challenges in retaining and hiring senior workers. One of those concerns is the work effectiveness and contribution of older employees. It is reported that $47 \%$ of the $55+$ category have some disability (Curran et al., 2007). These limitations include vision and auditory weakness; a decline in physical abilities; susceptibility to fatigue, illness, and injury; a reduction in cognitive capabilities (Coughlin, 1999). For the most part many of these limitations can be minimized by the use of technologies (Adler et al., 2008). Employers, taking a proactive approach to build boomer skill and productivity, can reap the benefits in the hiring and retaining of older employees. These advantages include lower costs for injuries and disabilities (Tishman et al., 2012).

Assistive technologies - devices or systems by which individuals with disabilities can maintain their capabilities - can help aging Boomers in remaining productive in the workforce. Probably one of the most famous users of assistive technology is Dr. Stephen Hawking, the world renown theoretical physicist, and cosmologist who suffers from Lou Gehrig's disease. Despite his many physical limitations, with the aid of a computer, he communicates, and even lectures at meetings and conferences, publishes ground-breaking scientific works, and serves as the Director of Research at the Centre for Theoretical Cosmology within the University of Cambridge. Intel Corporation, in conjunction with Walter Woltosz, CEO of Words Plus, developed a system whereby Hawking can communicate via a computer linked to a voice synthesizer (Medeiros, 2015). Intel is developing systems to help the disabled through the use of assistive technologies. They estimate that approximately $15 \%$ of the world population could benefit from these tools (Clancy, 2014).

\section{Types of Restrictions and their Remedies}

In this paper we examine some of the limitations aging workers may experience in their jobs and how existing and developing technologies could assist these older employees to remain productive in their profession despite some of these restrictions.

\subsection{Auditory Limitations}

An estimated $25 \%$ of people aged $65-75$ years and $70-80 \%$ of people over age 75 suffer from sensorineural hearing impairment associated with aging (known as presbycusis) (Sprinzl et al., 2010). This condition is typically caused by gradual changes in the inner ear. It most often occurs as a result of the cumulative effect of constant exposure to loud noises such as airports, construction sites and loud music.

If some hearing capabilities still exist, headphones with enhanced volume control are a cost effective way to address the problem. In fact, many younger workers typically wear headphones while working to play music or block out other office noises. Additional sound blocking structures in the office may be needed to avoid disturbing co-workers if sound amplification devices will not be used.

Those with more severe hearing disabilities have a number of products that could diminish these limitations. Speech recognition software products (e.g. Dragon Naturally Speak, Speech Assistant, or TalkText) provide assistance to these individuals. Programs of this nature have a training component to learn and understand the users' pattern of speech. These software packages are reported to have a high level of accuracy. By using these products to process the voice of others, hearing impaired individuals can participate in company discussions. 
These products have the added advantage that they can produce text at about 2-3 times the rate of normal typing.

For telephone conversation there are hearing aid compatible phones along with a wide array of voice text and video relay services to assist the hearing impaired. Furthermore, since much of the communication done nowadays is by e-mail or chat, voice and hearing communication is not as critical.

\subsection{Speech Limitations}

Although as indicated earlier, communication can be generally accomplished through the typewritten word, when not possible, reverse software - text to speech software including (Natural Reader, Ultra Hal, readClip) can be used as an alternative to permit individuals with speech impediments to communicate clearly. These software packages convert text to speech producing naturally sounding voices.

Dysarthria is a neurological disorder affecting speech. This condition affects the individual's ability to, among others, control his vocal quality, tone, pitch or volume. Augmented and alternative communication can assist (ASHA, 2015) people with severe speech and language limitations who must use other means of communication in order to express their thoughts, ideas, and desires.

Engineers have developed communication systems that produce voice output (SGD -speech generating devices, also referred to as VOCA - voice-output communication aids) to allow people with verbal limitations to actively participate in a conversation. By using a keyboard or touch screen, users select from a list of digitized recording of natural speech, or can construct phrases from a long list of symbols representing utterances that the user may wish to present. Apps have been developed for both tablet and smart phone profiles under both apple and android platforms (AAAC, 2015).Software companies are responding to those needing assistive technologies.

\subsection{Vision Limitations}

Lighthouse international reports that more than 285 million people worldwide have vision problems, of this group, 39 million are blind and 246 million have some level of visual deficiency. Predictions are that by 2020 this group will grow to about 75 million blind and 300 million visually diminished. About $58 \%$ of those who are blind worldwide are above the age of 60 (Lighthouse, 2014). Computer viewing difficulties range from small font size, type of background images, color discrimination, and visual field (Echt, 2002).

Devices exist that magnify the text and graphics on a computer screen. The user scans the page into the computer and uses the mouse to highlight and magnify different sections of the page. These devices are completely under the user's control. The user may identify and select a particular section of the page using the keyboard and mouse, or the device can be programmed to automatically move down the page at the viewer's pre-selected speed. Markers such as shading or various colors can help the viewer remember his place. The application of anti-aliasing to text prevents the display of jagged lines (for curves and diagonals) due to magnified text. Everything on the screen is magnified including icons, buttons, and mouse pointers.

For those who still retain most of their vision capabilities, a larger monitor that presents a larger display of the text and graphics while maintaining the same page format may be used. Adjusting the screen resolution may also be helpful in enlarging text and graphics.

In addition, the Windows Accessibility option can change the appearance of text and graphics on the screen. Among the options are increasing size of fonts, mouse cursor, scroll bar and buttons. The mouse cursor blink rate may be adjusted as well. The Accessibility feature can be used to magnify the entire screen or change the presentation of text (white on black background instead of black on white background).

Recently, companies that produce screen readers have added the capability of text-to-speech output. Thus, people with low vision can use a combination of magnification and speech options to enhance readability. If a user has high vision limitations, a screen reader may be a better option (American Federation for the Blind 2014).

More recently a device placed on one's finger serves as an audio device by converting text to audio in real-time. Researchers at the Massachusetts Institute of Technology (MIT) Media Lab have developed a FingerReader which is a camera like device and is worn on the operator's finger. The user moves his finger along the lines of text and the device "reads" the text. The words are then decoded and read aloud to the user with a synthesized voice. The wearer is guided to the beginning and end of the line, or paragraph by small vibrations at those junctures. The size and portability of this device addresses the needs of those with limited sight even while travelling or where more cumbersome equipment to assist them is unavailable. The FingerReader may also be programed to translate the text into other languages. Although the FingerReader is currently in the development stage, it has a high potential for being a very useful product in the future (Optometry Today, 2014).

Berkley and MIT researchers Barskey and Wetstein have developed an algorithm to modify a computer screen 
display based on a viewer's vision capabilities. The algorithm adjusts the light emitted from the pixels on the monitor so that it projects on the retina as a sharp image (Metz, 2014). This process might be most useful in cases where corrective lenses are not effective.

\subsection{Arthritis and Motor Skills Limitations}

Individuals who have difficulty using their hands to type may take advantage of voice to text technologies used by the hearing impaired. As mentioned earlier, the software products are quite sophisticated and have a learning component to adapt to the users' voice. In addition, a number of products compensate for the lack of fine motor skills. These devices include: oversize trackball mouse where the surface area of the mouse ball is significantly larger to ease in mouse manipulation. In addition, persons with hand tremors need not fear that the selected cursor position would be changed as a result of the hand shaking. If the user has better motor control in the foot, these mouse devices can be modified for foot use instead.

Adaptive keyboards assist users who lack sufficient precision motor control in their hands. Some keyboards have raised sections between the keys allowing them to slide their fingers on the proper key. Keyboard overlays allow regular keyboards to be transformed into adaptive ones. Some keyboards have word completion technology to anticipate the word being typed and thereby eliminating unnecessary keystrokes.

Although very expensive, and less common, eye tracking software can assist users with severely limited control, by following the individual's eye movements and facilitate their web surfing.

\subsection{Memory and Dementia}

As individuals age, their reasoning abilities and thinking processes impact the use of technology in their work. The development of new technologies demands the expansion of new skills and often adjustments in how tasks are performed. This poses a difficulty to older workers whose ability to learn new concepts and complex skills are diminished. The deterioration of attention ability may limit older workers in the multi-tasking and processing information from several sources simultaneously. Fast paced tasks where speed of performance is essential, such as data entry tasks, may also be incompatible with senior employees. ( Czaja \& Moen, 2004) .

Employers may accommodate their aging workforce by gradually introducing the newer technologies, allowing older workers to adapt slowly to the changes. Job distributions may be adjusted by assigning older workers to tasks where they have the most experience and for which they are most suited. Multiple shorter training sessions in a mixed training format in which the topic is presented, employees do the exercises, and they immediately and repeatedly apply topics learned and relate new skills to those already mastered, have been shown to be effective. Removing distractions such as noise, providing accommodations for the vision/hearing impaired) have also been helpful in integrating older workers into the new technological landscape.(Tishman et al., 2012).

\section{Conclusions}

Employers may hesitate retaining older personnel because of concern of declined worker performance, and added expense to accommodate these individuals. These fears are unsupported (Rice et al., 2003). Baby boomers are experienced, committed, loyal, and dedicated. They have a lot to contribute to the existing workforce.

Technological advances have eliminated many of the obstacles that would limit the employment of this productive class. Assistive technologies enable Baby Boomers to continue using their considerable talents to benefit employers. It would be most unfortunate if employers did not take advantage of this valuable resource (Mosner 2003). There are many apps developed for smart phones and tablets to assist users with limited capabilities see, for example (Douglas et al., 2012) for a list of over 500 apps used for for special education, some of which can be adapted to the needs of boomers, and (Doughty, 2011) for specific smart phone applications.

Retaining aging staff is also good business practice for the company. In addition to serving the needs of the stakeholders - employees, customers, stockholders, and the community at large, the company will benefit by reducing turnover costs (a cost that can reach 200 percent of an employee's salary) and slowing the talent drain of experienced workers. Proactive companies that show concern for their human resources have improved morale and a more productive and dedicated staff. This in turn increases their stature in the corporate world.

\section{References}

AAAC. (2015). Retrieved from http://appsforaac.net/ (visited 2/12/2015)

AARP. (2014). Retrieved from http://www.aarp.org/personal-growth/transitions/boomers_65/ (visited 7/23/2014)

ADA. (1990). Americans With Disabilities Act Of 1990, As Amended http://www.ada.gov/pubs/adastatute08.htm 
ADEA. (1975). Age Discrimination in Employment Act 1975 Retrieved from http://www.dol.gov/oasam/regs/statutes/age_act.htm

Adler, R., Friedman, L. W., \& Friedman, H. H. (2008). The Use of Information Technology to Create a Better Workplace for Individuals with Disabilities. Management Online Review. Retrieved August 11, 2008, from http://ssrn.com/abstract=2377837

American Federation for the Blind. Retrieved from http://www.afb.org/prodBrowseCatResults.asp?CatID=39

ASHA (2015). American Speech Language Hearing Association. Augmentative and Alternative Communication (AAC). Retrieved February 12, 2015, from http://www.asha.org/public/speech/disorders/AAC/

Calo, T. J. (2007). Boomer generativity: An organizational resource. Public Personnel Management, 36(4), 387-395. http://dx.doi.org/10.1177/009102600703600407

Clancy, H. (2014). Why Stephen Hawking is talking up Intel's 'assistive technology' innovation. Retrieved December 5, 2014, from http://fortune.com/2014/12/05/why-stephen-hawking-is-talking-up-intels-assistive -technology-innovation/

Coughlin, J. F. (1999). Technology needs of aging boomers. Issues in science and technology, 16(1), 53-60. Retrieved June 23, 2014, from http://issues.org/issues/16.1/coughlin/

Curran, K., Walters, N., \& Robinson, D. (2007). Investigating the problems faced by older adults and people with disabilities in online environments. Behaviour \& Information Technology, 26(6), 447-453. http://dx.doi.org/10.1080/01449290600740868

Czaja, S. J., \& Moen, P. (2004). Technology and employment. Technology and adaptive aging, 150-178. Retrieved from http://www.ncbi.nlm.nih.gov/books/NBK97338/

Doughty, K. (2011). SPAs (smart phone applications)-a new form of assistive technology. Journal of assistive technologies, 5(2), 88-94. http://dx.doi.org/10.1108/17549451111149296

Douglas, K. H., Wojcik, B. W., \& Thompson, J. R. (2012). Is There an App for that?. Journal of Special Education Technology, 27(2), 59-70.

Echt, K. V., \& Morrell, R. W. (2002). Designing web-based health information for older adults: Visual considerations and design directives. Older adults, health information, and the World Wide Web, 61-87.

Ford, R., \& Orel, N. (2005). Older Adult Learners in the Workforce New Dimensions to Workforce Training Needs. Journal of Career Development, 32(2), 139-152. doi: 10.1177/0894845305279165

Gist, J. R., Wu, K. B., \& Ford, C. (1999). Do Baby Boomers Save, And, If So, what For? Public Policy Institute, AARP. Retrieved from http://assets.aarp.org/rgcenter/econ/9906_do_boomers.pdf

Grossmann, I., Na, J., Varnum, M. E., Park, D. C., Kitayama, S., \& Nisbett, R. E. (2010). Reasoning about social conflicts improves into old age. Proceedings of the National Academy of Sciences, 107(16), 7246-7250. Retrieved June 24, 2014, from http://www.nas.org/content/earl/2010/03/23/1001715107

Johnson, R. W., Mermin, G. B., \& Resseger, M. (2011). Job demands and work ability at older ages. Journal of aging \& social policy, 23(2), 101-118. http://dx.doi.org/10.1080/08959420.2011.551465

Journal of Property Management (2012). Economy Impacts Boomers. Attitude Towards Retirement, 77(2), 6.

Kanfer, R., \& Ackerman, P. L. (2004). Aging, adult development, and work motivation. Academy of management review, 29(3), 440-458. http://dx.doi.org/10.5465/AMR.2004.13670969

Lighthouse International (2014). Retrieved July 23, 2014, from http://www.lighthouse.org/research/statistics-on-vision-impairment/prevalence-of-vision-impairment/

Medeiros, J. (2015). How Intel Gave Stephen Hawking a Voice. Wired Magazine. Retrieved January, 2015, from http://www.wired.com/2015/01/intel-gave-stephen-hawking-voice/

Metz, R., (2014). MIT Technology Review. Retrieved September 8, 2014, from http://www.technologyreview.com/news/529191/prototype-display-lets-you-say-goodbye-to-reading-glasse s/

Mosner, E., \& Spiezle, C. (2003). The convergence of the aging workforce and accessible technology. Microsoft Accessible Technology Group.

O’Hara-Devereaux, M., Mittman, R., Scott, C., et al. (2001). Seven Global work Trends. Emerging Technologies Outlook Program. Institute for the Future, Menlo, CA 
http://www.iftf.org/uploads/media/SR-757_Seven_Global_Work_Trends.pdf

Optometry Today (2014). Ring Could Help Blind Read Text. Retrieved July, 2014, from http://www.optometry.co.uk/news-and-features/news/?article=6111

Rice, F. S., Nakayama, S., \& Heiser, D. P. (2004). The accomodating workplace: making room for sensory disabled employees. $J$ Ind Technol, 20(1), 1-7.

Sprinzl, G. M., \& Riechelmann, H. (2010). Current trends in treating hearing loss in elderly people: A review of the technology and treatment options-a mini-review. Gerontology, 56(3), 351-358.

Tishman, F. M., Van Looy, S., \& Bruyère, S. M. (2012). Employer strategies for responding to an aging workforce. The NTAR Leadership Center, Rutgers, The State University of New Jersey. http://www.dol.gov/odep/pdf/NTAR_Employer_Strategies_Report.pdf

Toossi, M. (2006). New Look at Long-Term Labor Force Projections to 2050. A. Monthly Lab. Rev., $129,19$.

US BLS. (2012). US Bureau of Labor Statistics Education and Training Outlook for Occupations 2012 - 2022.

WIA. (1998). Section 508 of the Rehabilitation Act (29 U.S.C. 794d), as amended by the Workforce Investment Act of 1998. Retrieved from http://www.section508.gov/Section-508-Of-The-Rehabilitation-Act

\section{Copyrights}

Copyright for this article is retained by the author(s), with first publication rights granted to the journal.

This is an open-access article distributed under the terms and conditions of the Creative Commons Attribution license (http://creativecommons.org/licenses/by/3.0/). 